\title{
Ga-Na (Gallium-Sodium)
}

\section{H. Okamoto}

The Ga-Na phase diagram in [Massalski2] was redrawn from [1990Pel].

Based on essentially the same phase boundary data as [1990Pel], [2007Wan] calculated the Ga-Na phase diagram, as shown in Fig. 1. The melting reaction of $\mathrm{Ga}_{4} \mathrm{Na}$ was a congruent type in [1990Pel]. The peritectic type shown in Fig. 1 is likely because it requires a more symmetric peak in the liquidus boundary around $\mathrm{Ga}_{39} \mathrm{Na}_{22}$ [1991Oka]. The peak of the miscibility gap on the Na-rich side was estimated to be around $550^{\circ} \mathrm{C}$ in [1990Pel], which is very much lower than the calculated value in Fig. 1. Experimental data are not available for confirmation of either value.

\section{References}

1990Pel: A.D. Pelton and S. Larose, The Ga-Na (GalliumSodium) System, Bull. Alloy Phase Diagrams, 1990, 11(4), p 347-353

19910ka: H. Okamoto and T.B. Massalski, Thermodynamically Improbable Phase Diagrams, J. Phase Equilib., 1991, 12(2), p 148-168

2007Wan: J. Wang, W. Yuan, and M. Li, Thermodynamic Modeling of the Ga-N-Na System, J. Cryst. Growth, 2007, 307, p 59-65

Table 1 Ga-Na crystal structure data

\begin{tabular}{lccccc}
\hline Phase & Composition, at.\% Na & Pearson symbol & Space group & Strukturbericht designation & Prototype \\
\hline$(\mathrm{Ga})$ & 0 & $o C 8$ & $C m c a$ & $A 11$ & $\mathrm{Ga}$ \\
$\mathrm{Ga}_{4} \mathrm{Na}$ & 20 & $t I 10$ & $I 4 / m m m$ & $D 1_{3}$ & $\mathrm{Al}_{4} \mathrm{Ba}$ \\
$\mathrm{Ga}_{39} \mathrm{Na}_{22}$ & 36.1 & $o P 244$ & $P n m a$ & $\ldots$ & $\ldots$ \\
$(\beta \mathrm{Na})$ & 100 & $c I 2$ & $I m \overline{3} m$ & $A 2$ & $\mathrm{~W}$ \\
\hline
\end{tabular}

Weight Percent Sodium

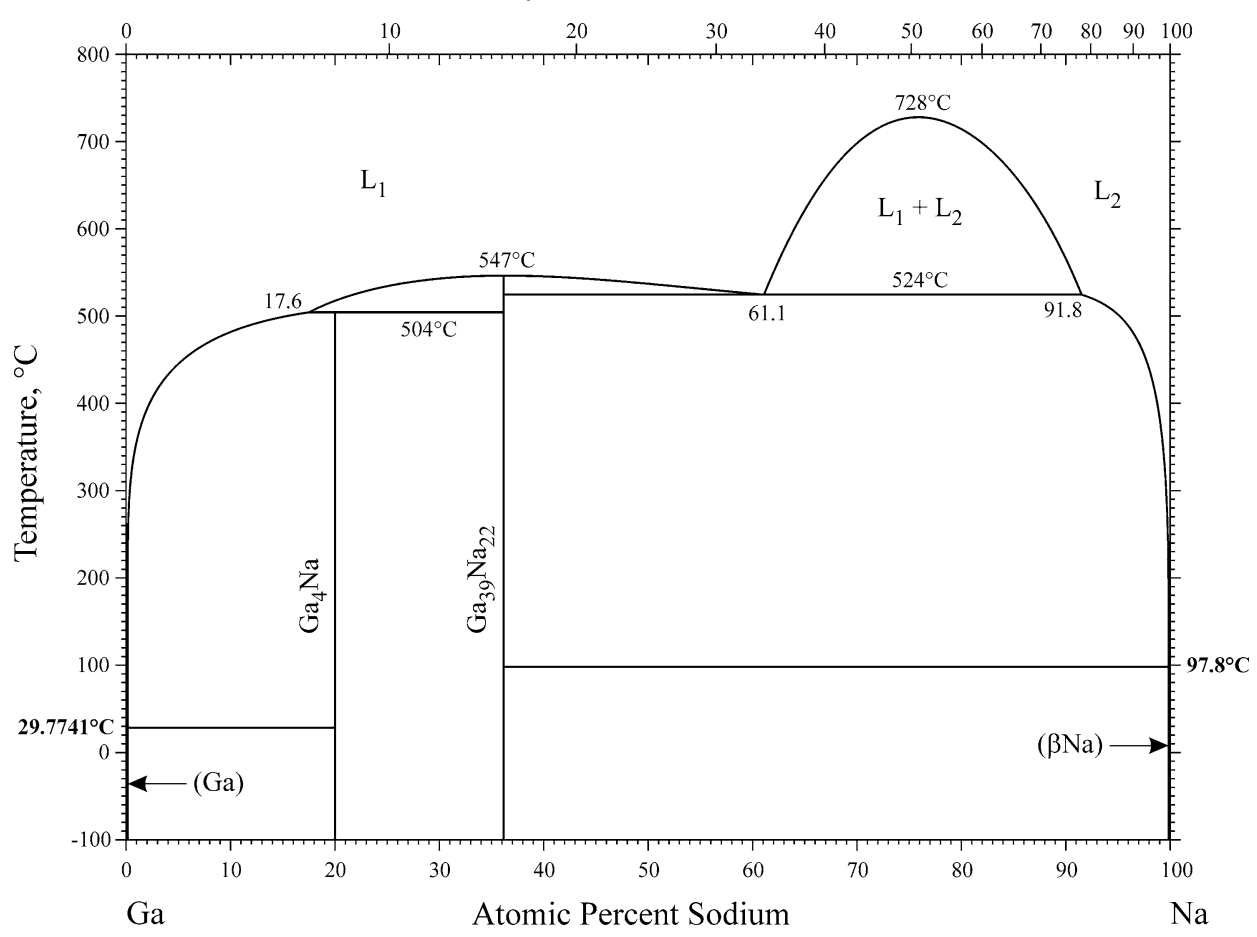

Fig. 1 Ga-Na phase diagram 